\title{
Beyond the Core: Who Has Larger Social Networks?*
}

Bas Hofstraa, Rense Cortenb, and Frank van Tubergen $c$

a Direct correspondence to Bas Hofstra, Graduate School of Education, Stanford University, 520

Galvez Mall, Stanford, CA 94305, U.S.A.; e-mail: bhofstra@ @stanford.edu.

b Utrecht University

c Utrecht University

\section{ACKNOWLEDGEMENTS}

We acknowledge Stanford University and the Stanford Research Computing Center for providing computational resources and support that contributed to these research results. We thank Tyler $\mathrm{H}$. McCormick for generously providing code for the network scale-up method from McCormick et al. (2010). Furthermore, early versions of this paper benefited from valuable feedback of Manja Coopmans, Jesper Rözer, Robert Krause, Jan Kornelis Dijkstra, Jeroen Weesie, and Vincent Buskens. We also thank seven Social Forces reviewers who provided insightful comments. Finally, this study benefited from discussions at the " 1 st International CILS4EU User Conference" in Mannheim. This research benefited from the support of the NORFACE research program on Migration in Europe - Social, Economic, Cultural and Policy Dynamics and from the support of several grants from the Dutch Scientific Organization (NWO): NWO onderzoekstalent [406-12004], NWO middelgroot [480-11-013], and NWO veranderingsstudies [481-11-004].

* This is the accepted, uncorrected version of our paper "Beyond the Core: Who Has Larger Social Networks" that appeared in Social Forces (soaa031). This version is similar in content to the published version, though the published version has been edited for length and copyedited by the journal. Please cite the published version of this study. 


\title{
Beyond the Core: Who Has Larger Social Networks?
}

\begin{abstract}
:
The sociological literature on social networks overwhelmingly considers the number of core social contacts. Social networks, however, reach far beyond this small number of social ties. We know little about individual variation in the size of such extended social networks. In this study, we move beyond core networks and explain individual variation in the extended social network size among youth. We use survey data of Dutch adolescents $(\mathrm{N}=5,921)$ and use two state-of-the-art measurements to compute extended network sizes: the network scale-up methods through Bayesian modelling and the observed number of contacts on Facebook. Among both measurements, we find that extended networks are larger among ethnic majority members, girls, and those who often engage in social foci. This highlights a crucial role for preferences and opportunity in the genesis of extended networks. Additionally, we find that differences between both network sizes (scale-up and Facebook) are smaller for girls and higher educated. We discuss the implications of these findings and suggest directions for future research.
\end{abstract}

\section{KEYWORDS:}

Facebook, Social Network Size, Scale-Up Method, Adolescents 


\section{INTRODUCTION}

Why are some individuals socially isolated but others highly connected? Scholars have devoted substantial attention on this question with regard to the number of people with whom individuals closely relate (e.g., Parigi and Henson 2014; Marsden 1987; McPherson et al. 2006). People seem to have close ties with only a few others. This conclusion often originates from studies on people's "core discussion network," where individuals are asked with whom they discuss "important matters." Scholars occasionally explain variation in the number of these core discussion partners (e.g., Burt 1984; Marsden 1987; McPherson, Smith-Lovin, and Brashears 2006). Findings from 1984, 2004, and 2008 (McPherson et al. 2006; Hampton, Sessions, and Her 2011) revealed that American adults had an average of two to three core ties.1 Dutch adults report fewer than three core discussion partners (Van Tubergen 2014). It was estimated that Americans on average had 17 alters with whom they had "trusting" relationships - i.e., good friends, discussion partners, or those trusted for advice or with money (DiPrete et al. 2011).

Current literature on variation in social network size thus often focuses on the number of core network contacts. Individuals' social circles, however, reach far further than this small group of five core or fifteen trusting ties (Gurevich 1961; De Sola Pool and Kochen 1978/79). Social networks consist of network layers (Dunbar 1998). The first two layers range from 2-3 core ties to 15-17 trusting social relationships (or sympathy group, Dunbar 2016). The two layers beyond those are hypothesized to have approximate sizes of 50 and 150 (Dunbar 2016).2 Beyond that is something that is defined as the extended social network. This layer includes all former layers and is the prime focus of this study.

We know surprisingly little about individual differences in the size of this extended social network, including close as well as the larger set of weaker ties. This lack of attention is remarkable 
from a substantive point-of-view, because the extended social network size relates to many societally relevant issues. For instance, more acquaintanceship ties facilitate access to information embedded in social networks (Granovetter 1973, 1983), and larger networks (occasionally measured via distal proxies) are associated with better health and well-being, and more social support (Holt-Lunstad, Smith, and Layton 2010). Yet, recent work started to explain individual variation in the extended network size (DiPrete et al. 2011; Lubbers, Molina, and ValenzueleGarcía 2019).

From a methodological perspective this research lacuna is less surprising. It is not straightforward to measure social ties. It is challenging to measure the number of core contacts (see Bearman and Parigi 2004; Small 2015).3 It stands to reason that measuring the number of ties becomes increasingly challenging when moving from close to distant ties (e.g., see Gurevich 1961). A growing body of literature, however, does develop methodologies to provide extended network size estimates (instead of explaining variation) (e.g., Killworth et al. 1998a; McCarty et al. 2001; McCormick et al. 2010). Earlier contributions to the development of such measurements provide a wide range of network size estimates, ranging from 108 (Killworth et al. 1998a) to 5,520 (Freeman and Thompson 1989). Methods to arrive at these point-estimates vary: asking respondents whom they knew from randomly drawn pages from phonebooks (Pool and Kochen 1978); using summation methods counting how many people respondents indicated they knew from a list of given relationships (McCarty et al. 2001); or counting the number of Christmas cards respondents send out (Hill and Dunbar 2003). Discrepancies in definitions on what constitutes social ties cause these vast differences.

Hence, we have little substantive knowledge about who has larger social networks beyond the core ties, and it seems difficult to come to an understanding on the measurement of extended 
networks. And these issues are interdependent: methodological issues lead to only few substantive studies on the extended network size. Here, we advance our understanding pertaining to both issues.

First, we answer a basic but fundamentally substantive question: what explains individual variation in the extended network size? As Kadushin (2012) puts it, "[we] do not as yet have a theory or a systematic study of the causes of these variations" (p. 72) in network size. Sociological literature mostly focuses on core networks and often explains its variation through individual preferences (McPherston et al. 2001) or broader social structures (Blau 1977; Feld 1981). Psychological endeavours show that personality factors (e.g., extraversion, agreeableness) relate to network size (Selden and Goodie 2018; Assendorpf and Wilpers 1998; Roberts et al. 2008; Selfhout et al. 2011). Yet, prior work hardly systematically considers individual variation in the extended network size. Here, we contribute in particular to sociological work (e.g., Zheng et al. 2006; DiPrete et al. 2011; Lubbers et al. 2019) that found differences in the extended social network size by gender, race, income, education, and social foci. In this paper, we test existing sociological explanations for the core network size and examine to what extent they apply to extended networks. Specifically, we elaborate a set of sociological mechanisms and derive our hypotheses based on those. Note that we do not directly observe these mechanisms, but assume, theoretically, that those mechanisms generate our outcome and therefore cause variation in the extended network size. We then confront these hypotheses with our data. Because theories on opportunities, preferences, and their interplay (Blau 1977; Feld 1981; McPherson, Smith-Lovin, and Cook 2001) are fundamental in core tie formation, we take these as our theoretical point-ofdeparture. We thus situate these theories in the context of this new outcome. Additionally, we develop a new hypothesis on the role of romantic partners, one that contrasts prior findings on the 
role of partners in core networks. And finally, we explore intuitions on differences in network size by education and gender based on network cognition (Brashears, Hoagland, and Quintane 2016). As such, we contribute new evidence on individual variation in extended network size.

Second, and uniquely, we use a set of similar predictors for two recent methods that provide extended network size estimates - we consider them in tandem. The first metric uses recent, stateof-the-art developments in the "network scale-up method" for a measure of the extended network size. In this method, respondents are asked via surveys how many people they know from various subpopulations (Killworth et al. 1998a; Killworth et al. 1998b; Zheng, Salganik, and Gelman 2006; McCormick, Salganik, and Zheng 2010; DiPrete et al. 2011; Maltiel et al. 2015). One can then "scale-up" to a population to calculate the network size. Our second metric considers unobtrusive, behavioral data and measures the number of contacts listed on individuals' online social media profiles (e.g., Gonçalves, Perra, and Vespignani 2011; Kanai et al. 2012; Pollet, Roberts, and Dunbar 2011; Dunbar et al. 2015; Dunbar 2016).

Both methods have their limitations, however. It is difficult, for instance, to put scale-up findings into a broader context and discussion of network sizes when covariates' correlations with network sizes are not compared with other measures of this unobserved (and often ill-defined) concept. Here, we consider the network scale-up estimates' lack-of-broader-context as an intrinsically valuable feature we explore. We build on prior work by Hampton, Sessions Goulet, and Purcell (2011) and compare two methodologically distinct but potentially similar concepts (despite likely absolute differences) within the same set of respondents and using the same predictors. This enables comparing our set of covariates among the two outcomes and explicitly modelling their differences. Hence, we better situate this measurement in discussions about the extended network size. The key limitation to measuring network size on social media is that they 
are highly selective: both in membership - does everyone become member? - and in privacy who shows their friends online? When some groups maintain more privacy online and become members less frequently than others (see Author DATE), estimated differences in network size based on public profiles between groups that are uncontrolled for such sample selections might become biased. Through combining detailed survey data with behavioural data from social media, we take into account sample selections in social media privacy and membership in an attempt to offset prior biases in social network size estimates.

In sum, we contribute new evidence on individual variation in extended network size and use and compare two state-of-the-art methods to capture extended network size. We provide this new evidence based on new, large, and linked empirical data. We focus on a surprisingly understudied target population in relation to network sizes: adolescents. Specifically, we longitudinally link survey data on Dutch adolescents $(\mathrm{N}=5,921)$ in 2012 (Kalter et al. 2015) to two data sources collected in 2014: (1) to survey data measuring these respondents' network size using the scale-up method and (2) to these respondents' observed Facebook profiles to measure their network size online (Author DATE; Jaspers and Van Tubergen 2017).

\section{THEORY AND HYPOTHESES}

At what distance do ties get included in the extended network size? In this study, we use a pragmatic definition of extended social networks provided by McCarty et al. (2001: 29) and DiPrete et al. (2011: 1242). We consider "all the contacts whom individuals know on a first name basis to be part of the social network, such that they would have a friendly chat if they were to meet randomly." Substantively, this definition relates to the societal outcomes discussed before. For instance, these contacts may grant meaningful connections in terms of knowledge to otherwise 
unknown sub-cliques. Methodologically, this definition provides a set boundary for persons recalling their network contacts similar to prior surveys (DiPrete et al. 2011).

\section{Opportunities and Homophily}

Meeting opportunities are key in the genesis of core social ties (Blau 1977; Feld 1981). One dimension of meeting opportunities are social foci. A focus is a "social, psychological, legal, or physical entity around which joint activities are organized" (cf. Feld 1981: 1016). Typical foci are associations, neighborhoods, work places, or schools. People engage in some of these foci, but not all. The idea is that those who share a focus will share activities, more so than individuals who do not share a focus. Sharing these activities facilitates positive interactions between people and brings them together in reciprocally valuable and rewarding situations (Feld 1981). Therefore, sharing a focus increases the likelihood for positive ties to form.

Research suggests that strong and weak ties are formed in some sort of focus (Wimmer and Lewis 2010). Many acquaintances are met, for instance, at associations, on vacation, and at parties among adults (Mollenhorst et al. 2008), on campus among students (Wimmer and Lewis 2010), at schools among adolescents (Smith, Maas, and Van Tubergen 2014), or at work among adults (Zheng et al. 2006). The importance of meeting opportunities for network formation thus crosscuts target populations. We use this idea and conjecture that those who engage more often in socially or recreationally orientated foci have more opportunities to get into contact and make acquaintances with other people compared to who engage less often in such foci - i.e., the extended network is a function of the time individuals spend in these foci. We examine five foci to capture adolescents' social life: going out (e.g., for a drink), associations (e.g., sports), concerts, family, religious meeting places, and potential workplaces. We hypothesize: 
Hypothesis 1: Individuals who spend more time (a) going out, (b) in associations, (c) visiting concerts, (d) with family, (e) at religious meeting places, and (f) have a job, have larger extended social networks.

A substantial body of literature focuses on the formation of social relationships and its relation to social network segregation (e.g., Kalmijn, 1998; McPherson et al. 2001; Mouw and Entwisle 2006; Currarini, Jackson, and Pin 2010). Besides the role of meeting opportunities, a common explanation for network formation is homophily (Kalmijn 1998; McPherson et al. 2001). Results in this line of research are that racial-ethnic segregation in networks is a ubiquitous feature of social life - often caused by (the interplay of) homophily and opportunity (Currarini et al. 2010; Wimmer and Lewis 2010; Smith et al. 2014). Given that racial-ethnic segregation in social networks is pervasive, we argue that the interplay of homophily and opportunity also relates to the extended network size.

For clarity, we reserve the term homophily for the preference of individuals to form relationships to similar others. This practice follows Wimmer and Lewis' (2010: 588) suggestion to use homophily exclusively for the tie generating mechanism (choice homophily in McPherson et al.'s [2001] terminology), not the empirical network outcome (segregation).

A second dimension of opportunity - besides foci - is the size of groups relative to other groups (Blau 1977). Homophily and relative group size work in tandem and cause disparities in the extended network size between ethnic minority and majority members. When people belong to a larger group, they have more opportunities to select members from within their own group, whereas minority members have fewer possibilities to make these homophilous choices. Ties among ethnically dissimilar people are costlier because they require higher initial investments to 
overcome cultural boundaries (Kalmijn 1998). Assuming that there is a limit on the investments one can make (e.g., in terms of time or emotional commitment), fewer ties are formed if the pool of potential alters includes relatively more dissimilar people. As a result, ethnic minorities establish fewer ties among their extended network than ethnic majority members. Furthermore, ties that are established - assuming that among ethnic minority groups ties are, on average, more often between dissimilar people - will be broken more frequently (cf. Smith, Maas, and Van Tubergen 2012).

In the Netherlands, approximately $79 \%$ of the population are so-called "Dutch majority" members (Statistics Netherlands, 2015). Much smaller in relative size are ethnic minority groups with an immigrant background. Minorities with a Turkish or Moroccan background, for instance, cover approximately $6 \%$ of the Dutch population. Hence, Dutch majority members - who prefer befriending other Dutch majority members - have ample possibilities to choose similar others as friends. Members of the ethnic minority have far fewer such opportunities and will therefore have fewer contacts. The group from which they prefer selecting their contacts is much smaller - i.e., the negative opportunity element limits their possibilities to exhibit a preference for similar others. Hence, relative differences in group sizes will result in an extended network size that is significantly larger for those people who belong to an ethnic background, for which the fraction in the population is larger, than for those whose representation is smaller. Such an interplay between homophily and group size affects the number of Twitter connections among students (Halberstam and Knight 2016), and DiPrete at al. (2011) find that racial minorities have smaller extended social networks among adults. In line this, we hypothesize:

Hypothesis 2: Dutch majorities have larger extended social networks than those from ethnic minority groups. 
Differences in the extended network size may also result from the ethnic segregation of social settings, because people of particular ethnic backgrounds self-select into foci in a non-random way. As foci increase the likelihood of a tie emerging between two people sharing a focus, this likelihood will be higher when potential contacts in foci share an ethnic background. This is again based on homophily, that conjectures that individuals inherently prefer befriending others with whom they share an ethnicity (McPherson et al. 2001). Hence, when there are many individuals sharing an ethnic background with in a focus, this person will more likely form more ties, as he/she has ample possibilities to make homophilous choices (see Feld [1982] among adults, and Author [DATE] among adolescents). Here, we focus on the school setting as a focus of tie formation among adolescents. We do not have information on the ethnic composition of the foci mentioned before (e.g., associations), nor is adolescents' school-of-choice completely exogenous. Some of the relative group size effects may result from non-random sorting of adolescents over foci that we do not address. We do, however, investigate the number of potential alters in schools and school classes who share an ethnic background with the respondent, as schools are important foci for tie formation among adolescents (McPherson et al. 2001). We hypothesize:

Hypothesis 3: Individuals who have a greater number of co-ethnic individuals in (a) their schools and (b) in their school classes will have larger extended social networks.

\section{Romantic Partners}

Previous research shows that individuals who are in romantic relationships have fewer strong relationships (Kalmijn 2003; Rözer, Mollenhorst, and Volker 2015). Features of strong relationships are that they require time, energy, and emotional investments (Granovetter 1973). This "social withdrawal" after finding a partner may thus be related to individuals' limited 
resources to maintain core contacts - people (initially) have only a limited amount of time, energy, and emotional capacity to maintain relationships with close contacts besides their romantic partners (Slater 1963; Kalmijn 2003).

This pattern, however, may differ for distal compared to close ties. When you befriend someone, especially when entering a romantic relationship, she/he may introduce you to many new acquaintances. These new acquaintanceships are far cheaper to maintain than stronger ties, as they involve less time, energy, and emotional investment. These new acquaintances introduce you to other new people, and so on. This may introduce a bandwagon effect where some people are in a more advantageous position to obtain new contacts continuously as compared to others. Romantic partners thus provide opportunities to meet new distal contacts (when social circles do not entirely overlap), and this departs from a "social withdrawal from strong ties" as these distal contacts are cheaper to maintain than stronger ties. Recent results seem to confirm such intuitions as Van Tubergen and colleagues (2016) found that those adults in a romantic relationship had more contacts. Note that those with many social ties may be more likely to enter in a romantic relationship as well, and that are unable to separate such reverse causality. We hypothesize:

Hypothesis 4: Individuals who indicate being in a romantic relationship have larger extended social networks than adolescents who are not.

\section{Education and Gender}

Research on "cultural omnivores" shows that some groups - generally those of higher status and education - pursue a broader range of leisure time activities than others (e.g., Peterson 1992). Some of this discrepancy is attributed to cognitive capabilities; some individuals are better capable of managing a broader range activities than others. Hence, some of the variation in the finding that 
those of high status and education engage in a broader range of activities is a byproduct of them being cognitively able to engage in such a diversity of activities. This may be a reason for larger network sizes among higher-educated individuals - they engage in a wider range of foci and, therefore, have more opportunities to befriend others than lower-educated individuals. The set of social foci we addressed before may not completely adjust for this indirect association.

Additionally, cognitive abilities in itself might be a factor in forming/maintaining of social ties (e.g., Dunbar, 1993). Specifically, cognitive abilities facilitate keeping track and maintaining all of the relationships one has - the better one is able to do so, the more contacts one has. As such, cognitive capabilities correlate with the extended network size. If we are to assume that educational attainment is somewhat correlated with such cognitive abilities, we can assume that there is variation in the capacity to maintain and keep into contact with many social contacts by educational level. Both mechanisms lead to our following hypothesis:

\section{Hypothesis 5: Individuals in higher educational track levels have larger extended} networks than individuals in lower educational track levels.

A consistent finding is that women's social networks differ significantly from men's. Women's networks are generally found to be larger (Moore 1990; Bastani 2007; Hampton et al., 2011; Van Tubergen 2014) and include more kin (Marsden 1987; Van Tubergen 2014). A notable exception to this pattern is DiPrete et al. (2011), who find no gender differences.

There are various mechanisms that may explain gender differences. First, women might cognitively be better equipped to manage networks than men. One indication of this is that women appear superior to men in recalling their contacts (Brashears et al. 2016). This may be a result of circumstances that shape women such they "develop a relatively greater ability to encode and 
recall social networks" (Brashears et al. 2016: 82). This is consistent with research showing that those in low power situations have greater knowledge of their social networks (Simpson et al., 2011), under the assumption that these circumstances imply lower status, prestige, or power positions of women compared to men (Bobbitt-Zeher 2007).4 Second, men and women may differ in their sociality, may have different dispositions towards social ties (Brashears et al. 2016), or may differ in their level of social activities. Each of these mechanisms may explain why women may have larger extended networks than man. Note that we do not test these mechanisms directly but explore these intuitions. Hence, we hypothesize:

Hypothesis 6: Girls have larger extended social networks than boys have.

\section{DATA}

We use data on Dutch adolescents from the "Children of Immigrants Longitudinal Survey in Four European Countries" (CILS4EU) (Kalter et al. 2015). We the Dutch data, as our measures of interest are included in that part, but data were collected in Sweden, Germany, and England too. We use the second and fourth waves, because the second wave contains the latest school-level data for the total set of respondents and the fourth wave measures the network size using the network scale-up method and the number of Facebook contacts. In these data, 14-15-year-old adolescents were followed for three years with a one-year time lag starting in 2010. The Dutch section

continued for four additional years under the heading "Children of Immigrants Longitudinal Survey in the Netherlands" (CILSNL) (Jaspers and Van Tubergen 2014, 2017). The surveys include measures on many characteristics, information on leisure time activities, and information about personal networks. The data are stratified by the proportion of non-Western immigrants 
attending schools. In these strata, schools were selected with a probability proportional to the school size using the number of students at the relevant educational track level.

At wave 1 (2010-2011), two classes were randomly chosen in schools, resulting in a sample size of 118 schools, 252 classes, and 4,963 (Nwave1) pupils participating in the Dutch survey.5 Classroom composition changes are common in the Netherlands. Therefore, respondents from wave 1 could be distributed among different classes at the time of the second wave. To ensure that many wave 1 respondents participated in wave 2 (2011-2012) as well, schools were asked to participate with all of the classes that wave 1 respondents were attending. Therefore, 2,118 new students were interviewed (attending the same class as original wave 1 respondents), and 3,803 students who participated in wave 1 participated in wave 2 as well $\left(76.6 \%\right.$; total $\left.\mathrm{N}_{\text {WAVE2 }}=5,921\right)$. In wave 4 (2013-2014) of the CILSNL, 4,073 (Nwave4) respondents participated, of which 3,611 had also participated in wave $2(88.7 \%)$.

\section{The Dutch Facebook Survey}

We link the survey data to unobtrusively collected behavioral data from Facebook using the Dutch Facebook Survey (DFS) (Author DATE). The DFS enriches the Dutch part of the CILS4EU and the CILSNL. The DFS was collected between June and September 2014. Of the 4,864 respondents that indicated Facebook membership in waves $3(2012-2013 ; \mathrm{N}=3,423)$ or $4(2013-2014 ; \mathrm{N}=$ $3,595)$ of the surveys, 4,473 $(92 \%)$ were tracked on Facebook. For the respondents who kept a public friend list, we downloaded their friend lists $(\mathrm{N}=3,373 ; 75.4 \%$ of tracked respondents $) .6$ 


\section{Data Structure and Sample Selections}

We longitudinally link two waves of survey data with behavioral data from Facebook. The number of observations is 5,921 for wave 2, 4,073 for wave 4, and 3,373 for the DFS (those with a public friend list). Some respondents keep their friend lists private on Facebook, whereas others keep it public (Author DATE). We consider those respondents for whom we can observe friend lists, as we want to measure their number of Facebook contacts in these lists. Potentially, we can compare 2,684 respondents' network sizes across the number of contacts on Facebook and the network scale-up measure; this is the number of respondents who participated in wave 4 of the survey and for whom we can observe their number of contacts on Facebook. Deletion of cases with missing values on the outcome variables leads to a set of 2,546 respondents. This is the number of cases we consider descriptively, and it captures the Facebook and scale-up network size measured roughly during the same period.

For our inferential analyses, we account for two types of selectivity: respondent attrition across waves 2 and 4 and selectivity in whose friend lists we observe on Facebook. We use Heckman selection models for both our network size measures, adjusting for respondents' gender, educational level, and ethnic background (outlined below) in the selection equations (detailed later on). These variables are key because both Facebook privacy as well as panel attrition may be nonrandomly distributed among these groups (Author DATE). As inclusion criteria for the inferential analyses, cases need to have non-missing values on independent variables in wave $2(\mathrm{~N}=5,488$ out of $\mathrm{N}_{\text {WAVE2 }}=5,921,7.3 \%$ item non-response across independent variables). Figure 1 summarizes the data sources and their observations and Table 1 specifies conditions for inclusion in the analyses. 


\section{Survey data (CILS4EU/CILSNL)}

2012

2014

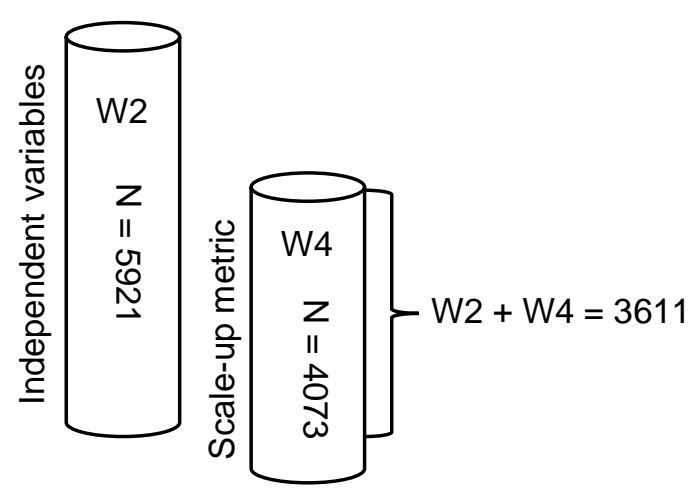

Online network data (DFS)

2014

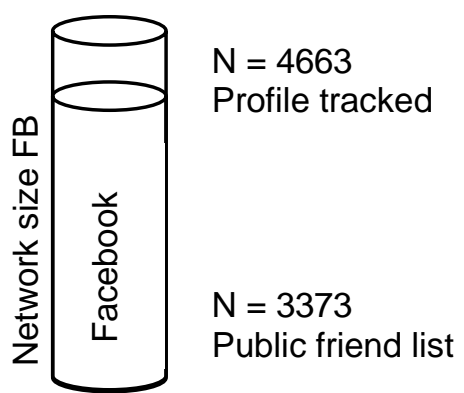

Figure 1. Schematic overview of the used data sources.

Table 1. Overview of the used criteria for data inclusion in the analyses.

\begin{tabular}{lc}
\hline \hline & $\mathrm{N}$ \\
\hline $\begin{array}{l}\text { Inclusion criteria for descriptive analyses } \\
\text { Public Facebook friend list + Non-missing network scale-up }\end{array}$ & 2,546 \\
$\quad \begin{array}{l}\text { Inclusion criteria for inferential analyses } \\
\quad \text { Non-missing values independent variables in W2 }\end{array}$ & 5,488 \\
\hline
\end{tabular}

\section{Independent Variables}

Foci.- Each independent variable is measured in wave 2 of the CILS4EU unless stated otherwise.

Respondents were asked five questions on how often they spend time in foci. They could indicate on a five-point scale (1-never, 2-less often, 3-once or several times a month, 4-once or several times a week, and 5-daily) how often they go out (e.g., bars/nightclub/etc.), spend time in associations (sport/music/etc.), visit concerts or DJs, spend time with family, and visit religious meeting places. Hence, we consider these five variables showing the time respondents spend in these foci. Additionally, respondents indicated whether they had a part-time job (yes/no) and we take this binary indicator into account as well. 
Ethnic Background.- We categorize respondents into ethnic background groups according to the country of birth of their biological parents, which is standard practice in scholarship on Dutch ethnic groups (e.g., Smith et al., 2014). When adolescents have one Dutch-born parent, they are categorized in the ethnic category of the parent not born in the Netherlands. When respondents have parents born in different non-Dutch countries, they are categorized in the mother's birth country. This categorization is regularly applied and used by Statistics Netherlands (2012). We categorize respondents into "Dutch ethnic majority" and "Ethnic minority" categories in line with Hypothesis 2 that contrasts these two groups (and because observations are low if we split into different ethnic groups). The "Ethnic minority" category includes adolescents of all non-Dutch ethnic origins such as, for instance, Dutch Caribbean, German, and Turkish and Moroccan youth.

Number of co-ethnic in Class.- We measured the number of students in a class who share ethnic backgrounds with respondents: the number of Dutch majority members for those of the Dutch ethnic majority, the number of Turkish origin for those of the Turkish ethnic minority, etc. We did use detailed ethnicity categories for the "Other" ethnic background. For instance, we counted the number of Dutch Caribbean in a class for those of Dutch Caribbean ethnic background.

Number of co-ethnic in School.- In a similar way, we calculated the number of schoolmates who share an ethnic background with the respondent (excluding classmates, as we aim to separate the effects of classmates and school mates). This variable was measured from secondary data that were obtained from the Dutch inspectorate of Education. 
Romantic Partner.- We measure whether the respondent indicated being in a romantic relationship (yes/no: “Do you have a boyfriend/girlfriend?").

Educational Track-Level.- When Dutch adolescents transition to high school, they are placed in different educational tracks that differ in their type of education and level. We measured this categorization with an ordinal variable: 1-preparatory vocational education (Dutch: VMBO), 2senior general (Dutch: HAVO), and 3-university preparatory education (Dutch: VWO).

Gender.- We measure whether respondents indicated being a girl (1) or boy (0). Table 2 reports the descriptive statistics of the independent variables.

Table 2. Descriptive statistics for the independent variables $(N=5,488)$.

\begin{tabular}{lllll}
\hline \hline & Min. & Max. & Mean & SD \\
\hline Foci (H1) & 1 & & & \\
$\quad$ Going out & 1 & 5 & 2.761 & 0.916 \\
$\quad$ Associations & 1 & 5 & 3.339 & 1.256 \\
$\quad$ Concerts & 1 & 5 & 1.932 & 0.762 \\
$\quad$ Family & 1 & 5 & 3.176 & 0.830 \\
$\quad$ Religious meeting places & 0 & 1 & 1.659 & 1.019 \\
$\quad$ Job & & & 0.563 & - \\
Similarity of potential contacts (H2 + H3) & 0 & 1 & & \\
$\quad$ Ethnic minority & 0 & 28 & 0.294 & - \\
$\quad$ Number co-ethnic class & 0 & 2300 & 688.252 & 625.294 \\
$\quad$ Number co-ethnic school & 0 & 1 & 0.253 & - \\
Romantic Partner (H4) & & & & \\
Educational track level (H5) & 0 & 1 & 0.537 & - \\
$\quad$ Vocational & 0 & 1 & 0.255 & - \\
$\quad$ Senior general & 0 & 1 & 0.208 & - \\
$\quad$ University preparatory & 0 & 1 & 0.510 & - \\
Girls (H6) & & &
\end{tabular}

Source: Survey data from the CILS4EU wave 2 


\section{Confounding Factors}

For those who are new to Facebook and less-frequent users, their number of contacts on Facebook is more remote from their overall number of connections than for more-experienced and morefrequent Facebook users. Therefore, we control for whether or not respondents were an early Facebook adopter in the Netherlands using a pre-defined classification - i.e., members before 2010 were early adopters (Author DATE) - and for the number of hours respondents spend each day on Facebook. The number of contacts on Facebook is correlated with Facebook membership duration in years $(r=.268 ; p<.001$; Median year of membership $=2010)$ and with the amount of hours spent on Facebook per day $(r=.154 ; p<.001$; five categories, where median hours per day $=1$ hour or less). To help guide respondents and to reduce lack-of-response errors, the question for time spend on Facebook was asked using interval censoring ("How much time per day do you spend on Facebook?": 1-one hour or less to 5-four hours or more). We categorize Facebook membership duration in years into two categories instead of keeping yearly categories to ensure large enough sample size in each cell (e.g., only 75 respondents became Facebook members in 2005-2007). Early adoption of Facebook comes from the DFS, and the amount of hours spent on Facebook each day originates from wave 4 of the CILSNL. To maintain our sample size of 5,588 of non-missing cases in wave 2, we include categories for respondents that did not participate in wave 2. Finally, we control for respondent's age in months - both when the Facebook and the scale-up data were collected - because recent work shows network sizes differ by age (Lubbers et al. 2019). Figure 2 depicts correlations between our covariates. 


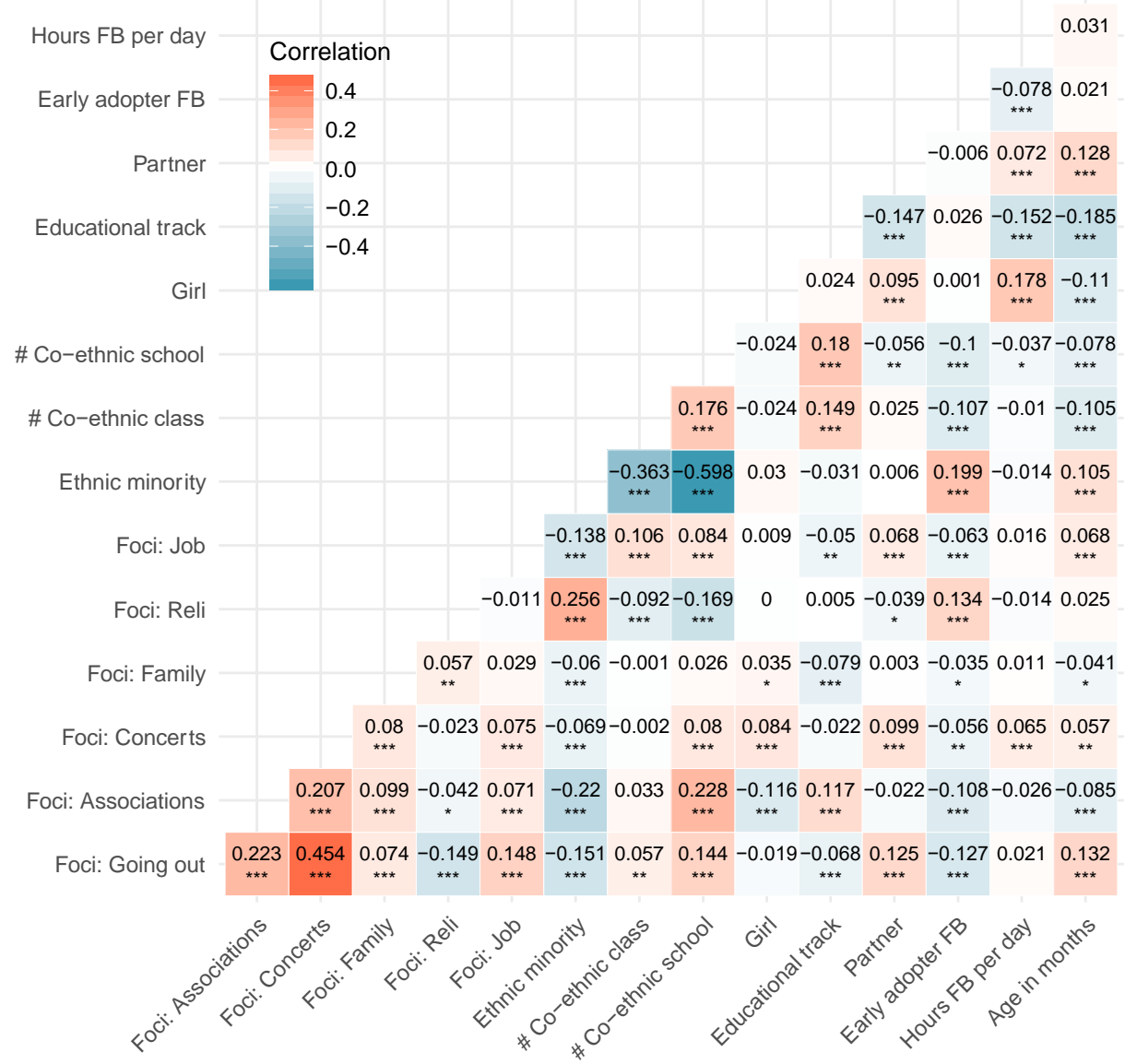

Figure 2. Correlations between covariates $(*=p<.05 ; * *=p<.01 ; * * *=p<.001)$.

\section{MEASURING THE EXTENDED SOCIAL NETWORK SIZE}

\section{The Number of Contacts on Facebook}

On Facebook, members send (and receive) friendship invitations to (and from) others, who can accept/decline the invitation. When accepted, a friendship tie within people's friend list shows an undirected, reciprocated friendship between two users. Using the DFS, we measure the number of contacts respondents have in their Facebook friend lists as the network size on Facebook. Note that this metric does not (nor do we intend to) distinguish between a close friends or distal acquaintances on Facebook. Yet, most empirical research suggests that Facebook contacts at least 
started out as and are likely meaningful, offline ties that may be categorized under our definition of extended network ties. For instance, only .4 percent of online friendships are online-only among U.S. college students (Mayer and Puller 2008), that primarily use online networks to strengthen and maintain their offline relationships (Ellison, Steinfield, and Lampe 2007, 2011) and befriend others on Facebook when they share dorms, residencies, and academic majors (Wimmer and Lewis 2010). Additionally, about $80 \%$ of adolescents use online networks to maintain offline contacts (Subrahmanyam et al. 2008), and the majority ( 77\%) of adolescents' online ties was formed offline (Reich, Sybrahmanyam, and Espinoza 2012; Van Zalk et al. 2014). Danish students also consistently meet a large fraction of their Facebook friends offline (Sapiezynski et al. 2018). U.S. adults are Facebook friends with family (93\%), current friends (91\%), past friends (87\%), colleagues (58\%), and neighbors (36\%) (Duggan et al. 2015). Finally, neighborhood, school, and school class gender and ethnic compositions highly align with adolescents' Facebook network compositions (Author DATE).

\section{The Network Scale-Up Method}

The network scale-up method (Killworth et al. 1998a; Killworth et al. 1998b) uses surveys to estimate individuals' extended social network size (McCormick et al. 2010). The method was developed to provide estimates of hard-to-reach populations (e.g., estimating the seroprevalence of HIV in a given target population). The method works as follows. Consider a population of size $N$. To estimate network size, one can ask respondents the number $n$ randomly chosen members of the population an individual knows. However, the larger the population $N$ is, the lower the likelihood that two randomly drawn persons know one another. 
The network scale-up method circumvents this issue and asks individuals whether they know an entire set of people in a population simultaneously. For instance, it asks "How many people do you know that are named Thomas?" instead of asking which of the $\sim 40,000$ people they know in the Netherlands are named Thomas (Meertens Institute 2016). When a respondent then indicates that she/he knows two people named Thomas, one can estimate the total network size by assuming one (a) knows 2/40,0000 of the entire population of persons named Thomas and (b) that this same proportion equally applies to the entire population ( $\sim 17$ million in the Netherlands),

$$
\frac{2}{40,000} \times(17 \text { million })=850
$$

The estimate's precision increases by averaging responses to multiple categories of people, e.g., for samples of different subpopulations (e.g., detainees, etc.). This yields what is called the basic scale-up estimator:

$$
\text { Scale-up degree }{ }_{i}=\frac{\sum_{k=1}^{K} y_{i k}}{\sum_{k=1}^{K} N_{k}} \times N,
$$

where $y_{i k}$ is the number of people person $i$ knows in subcategory $k, N_{k}$ is the size of subcategory $k$, and $N$ is the size of the population (cf. McCormick et al. 2010). Generally, the subpopulations that are prompted to respondents are occasionally referred to as "How many X's do you know?", where the X's refer to the subpopulations.7

We implemented this in the CILSNL by presenting the following statement (translated from Dutch) to respondents:

The next questions are about all the people you know personally in the Netherlands. By knowing personally, we mean that you know the name of that person and that you would have a chat if you were to meet him or her on the street or in a shop. 
This statement implies reciprocal relationships, which makes it suitable for comparisons with the number of contacts on Facebook (which are reciprocal). Respondents were prompted to recall contacts they know personally in the Netherlands. This phrasing is crucial as it allows to scale-up adolescents' recalled ties exclusively to the Dutch population and, therefore, prevents two difficult to solve. First, many adolescents of immigrant background have transnational ties (Schimmer and Van Tubergen 2014) and, second, those adolescents who live geographically close to national borders (e.g., Belgium and Germany) might have many social ties across borders. Our statement thus prevents respondents to recall contacts that we are unaware of and, consequently, be unable to scale-up to because we don't know the reference group. Additionally, contacts in the Netherlands neatly relate to "meaningful acquaintances" able to provide help, support, and information in that specific national context. In sum, our approach defines a clear and substantive network boundary for our respondents, and one that is convenient methodologically.

Respondents indicated for fifteen populations how many contacts they had in the Netherlands. Respondents were prompted with five names (Thomas, Kevin, Anne, Melissa, and Moham(m)ed) on the question "How many people do you know personally with the following name?" They indicated whether the number of people they knew fell within the numerical ranges of $0,1,2-5,6-10,11-20,21-50$, or more than 50 . To ease the answering process for respondents and to reduce lack-of-response errors, the questions were asked using interval censoring. This same strategy was used by DiPrete and colleagues (2011: 1251). We follow their strategy and take midpoints of the intervals. Following the strategy of Lubbers et al. (2019: 60), we take the value 11 as the largest number even when respondents indicate to know more individuals with a given name. This is to reduce recall errors that have been shown to grow significantly when respondents say they know many people in subpopulation. The typically Dutch names (first four) represent 
names of both genders from parents with either a higher or lower status background: Anne (girl, high status), Melissa (girl, low status), Thomas (boy, high status), and Kevin (boy, low status) (see Bloothooft and Onland 2011: 34). The fifth name represents the two most-prevalent versions in the Netherlands of the typical Islamic boy name Muhammed: Moham(m)ed (Meertens Instituut 2016). Including these different names will help mitigate the possibility that individuals from different societal strata, genders, and ethnicities know more or less of the prompted X's. Second, using the same interval-censoring, respondents indicated how many contacts they knew living in five medium-to-large cities in the Netherlands distributed equally among geographical regions (Groningen [north], Utrecht [center], Maastricht [south], Den Haag [south-west], Zwolle [northcenter]). Third, three scale-up questions asked respondents how many contacts they had that were currently enrolled in one of the three distinct levels of tertiary education in the Netherlands (MBO [tertiary lower-vocational], HBO [tertiary higher-vocational], University), again attempting to increase precision by prompting respondents to estimate their number of contacts across three distinct Dutch educational strata. We take midpoints, and given that it is likely to know many individuals in any of these cities, or in any of the educational levels, we take 51 as the largest number. Finally, respondents indicated how many people they knew that were arrested in the last 12 months by the police or that were in jail. For the same reason as for the prompted first names, we use midpoints and take 11 as the largest value. See Appendix A for the population numbers among these groups.

Bayesian Estimation Using the Scale-Up Module.- Through our selection of X's we attempt to mitigate that some groups may know more people within specific subpopulations than other groups. This issue is well-known and is referred to as barrier effects (or non-random mixing, 
segregation, etc., see Zheng et al. 2006; McCormick et al. 2010; DiPrete et al. 2011; Maltiel et al. 2015). We already mitigate some of these barrier effect by carefully selecting a set of prompts that crosscut social strata and through sampling from one cohort of adolescents (i.e., low age heterogeneity in reporting of known individuals). Yet, this phenomenon may still bias the basic scale-up estimator from Equation (2). A second issue with the basic scale-up estimator are transmission errors: respondents may not always be perfectly aware of alter characteristics (e.g., whether a network contact lives in a given city).

Maltiel et al. (2015) propose to use Bayesian methods using Markov Chain Monte Carlo (MCMC) algorithms as an attempt to mitigate both barrier effects and transmission errors. We follow their approach, and adjust the basic estimator in three ways. We allow for (1) a random effect for degree to regularize the degree estimates and to reduce sensitivity to extreme values, (2) the probability that a given person $i$ knows someone in group $k$ to vary randomly (instead of it being fixed) across individuals (accounting for barrier effects), and (3) a multiplier to the binomial proportion of people known in a given subpopulation (accounting for transmission errors). For mathematical details, we refer to Maltiel et al. (2015: 1251) and we summarize their model in Appendix C. We use the "NSUM" R package (Maltiel and Baraff 2015). For model priors, we Maltiel et al. (2015) and calculate starting-point parameters with the basic scale-up estimator, yielding a mean degree, a standard error (see Endnote 7), and an individual-level degree. We run 40,000 iterations of the MCMC algorithm (using closed-form Gibbs sampling), retain 4,000 of the chains, and calculate the average network size over these 4,000 estimations per individual.

Ideally, we would directly fit a model of network size; however, the available methods requires us to estimate the size of a hidden population even though we are aware of all 15 population sizes in our scale-up module. Therefore, to circumvent the limitations in the available 
methods and because we do not want to arbitrarily select one, we run the estimation process 15 times. In each trial, we hold out one of the 15 populations as the unknown one and run our inferential tests on each of the 15 generated scale-up network sizes. Results are similar across all trials and the fifteen generated network size outcomes correlate $~ .95$. Given that the trials yield similar results, we select the trial with the "number of people known in prison" as the unknown one to present as the main analyses in this paper. Finally, we ran the Bayesian estimation process ten times where in each trial we randomly remove two of the 15 populations to find out whether results are sensitive to different subset of prompts (so using 13 populations in each trial). Here too, results are mostly similar to those presented.

\section{RESULTS}

\section{How Large Are Extended Social Networks?}

We first describe the obtained extended network sizes, then analytically test our hypotheses, and finally consider differences between the two metrics. Table 3 compares the scale-up and Facebook network size. The median extended social network size using our scale-up procedure is approximately 892, compared to a median number of Facebook contacts of approximately 351 and they correlate moderately $(r=.314 ; p<.001)$. The scaling factor from the Facebook to the scaleup network size is 2.54 , which approximates the scaling factor of 2.83 found by Hampton et al. (2011). Figure 3 depicts the density distributions for both metrics and show a tendency of a few highly connected individuals and a majority of individuals with comparatively few contacts. This resembles DiPrete and colleagues' plot of the number of acquaintances among Americans (2011: 1254). The median network size of 892 of the scale-up method is substantially higher compared to that of estimates using similar methods. Prior estimates of extended network sizes using the 
scale-up method are in the range of 472-610 (Zheng et al. 2006; McCormick et al. 2010; DiPrete et al. 2011; Lubbers et al. 2019). Perhaps this is because our sample exclusively includes young adults (i.e., 18-19 year olds) that might be more socially active across a wider array of foci compared to members of more general target populations (e.g., adults). Findings using early behavioral data from before 2009, primarily from the microblogging website Twitter or from the social network site Facebook, show an average number of social media contacts of 180-200. As these platforms grew more popular, the number of friends seemed to grow accordingly. Our average Facebook network size is on par with that of recent work - e.g., 371 versus 420 (Tulin, Pollet, and Lehmann-Willenbrock 2018).8, 9

Table 3. Descriptive statistics on the extended social networks $(N=2,546)$. a

\begin{tabular}{llllll}
\hline \hline & $25 \% \mathrm{~b}$ & $50 \%$ & $75 \%$ & Mean & SD/SE \\
\hline Number of friends on Facebook & 236 & 351 & 491 & 381.710 & 206.710 \\
Scale-up estimator (Bayesian) & 630.985 & 892.744 & 1295.287 & 980.387 & 529.244 \\
\hline a Numbers are based on observations for respondents who maintained public Facebook profiles as well as \\
who completed the network scale-up questions. \\
b These statistics are the 25th percentile, median, and 75th percentile of these variables in these data.
\end{tabular}

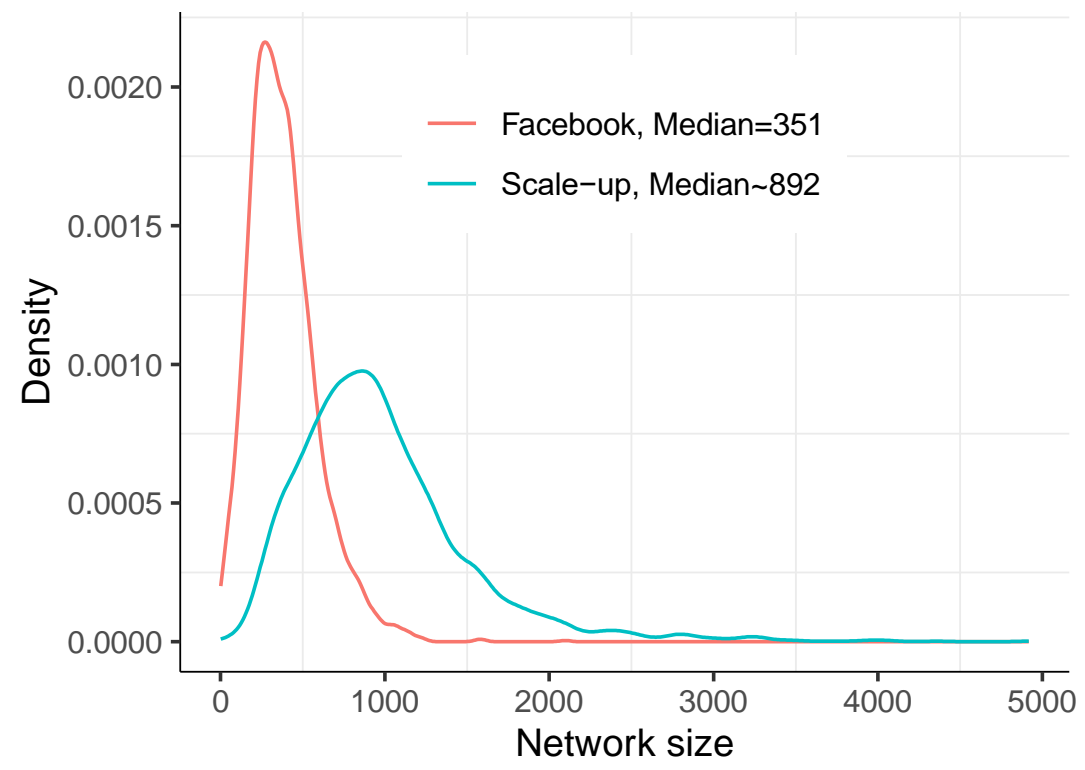

Figure 3. Density distributions for the extended social network size using the scale-up method and the number of Facebook friends $(N=2546)$. 


\section{Who Has Larger Extended Networks?}

We use Heckman selection models to test our hypotheses (Heckman 1979). Formally, this takes the following form. The linear regression equation is

$$
y_{j}=\beta_{0}+\beta_{1} X_{j}+\ldots+\beta_{k} X_{j}+\varepsilon_{1 j}
$$

where $\beta_{0}$ represents a constant, $\beta_{1} X_{j}+\ldots+\beta_{k} X_{j}$ represents a vector of independent variables, and $\varepsilon_{1 j}$ represents the error term. The selection equation is

$$
z_{j} Y+\varepsilon_{2 j}>0
$$

where the errors terms of both equations are allowed to correlate,

$$
\operatorname{cor}\left(\varepsilon_{1 j}, \varepsilon_{2 j}\right)=\rho
$$

In the linear regression equation, we regress both network sizes on our independent- and confounding variables. We adjust for ethnic background, gender, and educational track level in the selection equation. We cluster-correct standard errors for the school cluster to which adolescents belong in wave 2 (to adjust for similarities of students originating from the same school), but results do not very with either robust, non-corrected, or cluster-corrected standard errors. Selection (yes/no) here means "surviving" from the second wave of the CILS survey to being observed with a network size on (i) Facebook and (ii) on the scale-up metric. We use Full-Information Maximum Likelihood estimation. Heckman selection models produces regression weights that are less-biased by selection effects. It also produces a correlation between the errors of both equations. These correlations are .959 (Facebook) and .981 (scale-up). A Wald test of independent equations for both outcomes shows that $\rho \neq 0(p<.001)$. In Appendix E we show that ethnic minorities (Facebook, scale-up), boys (scale-up), and lower educated (scale-up) are indeed less likely to be observed. These results imply outcome selectivity and justifies our modeling strategy. It also implies downward/upward biased estimates for some groups if we do not model this selectivity. A 
classic example of such patterns is salary, e.g., men who do not work are likely to have low salaries if they would work. Hence, observed wages of working men are biased upward. We see a similar pattern here: ethnic minorities (or boys, or lower educated) who are less likely to be observed have lower network sizes. Not modeling that upwardly biases observed minorities' (or boys', or lower educated's) networks.

Because the distributions of both outcomes are not unusually skewed (Skewness Facebook $=1.172 ;$ Skewness Scale-up = 1.778), to allow for intuitive interpretation of coefficients, and following DiPrete et al. (2011), we use linear regressions in the substantive Heckman equation (see Appendix D for results without adjusting for selections, see Appendix E for selection coefficients). Table 4 depicts the results of our analyses and discuss them below. 
Table 4. Maximum-likelihood estimation results of the extended network size measured via the number of Facebook contacts and the scale-up method using Heckman selections. a, b

\begin{tabular}{|c|c|c|c|c|c|c|}
\hline & \multicolumn{3}{|l|}{ Facebook } & \multicolumn{3}{|l|}{ Scale-up } \\
\hline & Coef. & $\mathrm{SEb}$ & $p$-value & Coef. & Sea & $p$-value \\
\hline Constant & 168.852 & 80.729 & 0.036 & -92.775 & 178.841 & 0.604 \\
\hline \multicolumn{7}{|l|}{ Foci (H1) } \\
\hline Going out & 46.807 & 4.104 & $<0.001$ & 56.933 & 8.362 & $<0.001$ \\
\hline Associations & 17.046 & 3.310 & $<0.001$ & 22.763 & 5.820 & $<0.001$ \\
\hline Concerts & 12.300 & 5.446 & 0.024 & 28.896 & 12.145 & 0.017 \\
\hline Family & 1.255 & 3.698 & 0.734 & 9.897 & 8.480 & 0.243 \\
\hline Religious meeting places & -3.150 & 3.849 & 0.413 & 18.516 & 7.244 & 0.011 \\
\hline Job (yes/no) & 29.586 & 6.397 & $<0.001$ & 6.117 & 14.347 & 0.670 \\
\hline \multicolumn{7}{|l|}{ Similarity of cont. $(\mathrm{H} 2+\mathrm{H} 3)$} \\
\hline Ethnic minority (ref. maj.) & -99.704 & 18.413 & $<0.001$ & -125.339 & 38.182 & 0.001 \\
\hline \# Co-ethnic Class & 1.576 & 0.795 & 0.047 & 0.949 & 2.144 & 0.658 \\
\hline \# Co-ethnic School & -0.009 & 0.010 & 0.367 & 0.020 & 0.021 & 0.330 \\
\hline Rom. partner (yes/no) (H4) & 29.741 & 7.384 & $<0.001$ & 5.340 & 17.742 & 0.763 \\
\hline \multicolumn{7}{|l|}{ Education (H5) } \\
\hline Vocational (ref.) & Ref. & Ref. & Ref. & Ref. & Ref. & Ref. \\
\hline Senior general & 38.687 & 21.179 & 0.068 & 121.722 & 41.529 & 0.003 \\
\hline University prep. & -8.410 & 14.951 & 0.574 & 129.472 & 40.563 & 0.001 \\
\hline Girl (ref. Boy) (H6) & 30.768 & 9.619 & 0.001 & 144.340 & 20.572 & $<0.001$ \\
\hline \multicolumn{7}{|l|}{ Confounders } \\
\hline \multicolumn{7}{|l|}{ Early adopter of FB } \\
\hline No (ref.) & Ref. & Ref. & Ref. & - & - & - \\
\hline Yes & 53.946 & 5.533 & $<0.001$ & - & - & - \\
\hline Non-participation w2 & 32.401 & 19.978 & 0.105 & - & - & - \\
\hline \multicolumn{7}{|l|}{ Hours FB per day } \\
\hline$<1$ hour (ref.) & Ref. & Ref. & Ref. & - & - & - \\
\hline 1-2 hours & 40.448 & 7.252 & $<0.001$ & - & - & - \\
\hline 2-3 hours & 53.702 & 11.204 & $<0.001$ & - & - & - \\
\hline 3-4 hours & 72.971 & 15.517 & $<0.001$ & - & - & - \\
\hline$>4$ hours & 45.085 & 24.002 & 0.060 & - & - & - \\
\hline Non-participation w2 & 9.015 & 8.087 & 0.265 & - & - & - \\
\hline Age in months & -1.317 & 0.352 & $<0.001$ & 0.375 & 0.782 & 0.632 \\
\hline Observations & 5463 & & & 5448 & & \\
\hline Censored observations & 2776 & & & 2328 & & \\
\hline Uncensored observations & 2687 & & & 3120 & & \\
\hline Log pseudolikelihood & -21214 & & & -26973 & & \\
\hline$\rho$ & 0.961 & & & 0.981 & & \\
\hline
\end{tabular}

\section{Opportunities and Homophily}

As shown in Table 4, adolescents who spend more time going out, in associations, and going to concerts (all at least $p<.05$ ) have a larger number of contacts both on Facebook and in the scaleup measure. The magnitude of these correlations are large. Specifically, a one-unit increase (e.g., 
from once a month to once a week) in going out, visiting associations, or going to concerts, adolescents gain approximately 46, 17, and 12 Facebook contacts, respectively. A one-unit increase in these same foci increase the number of friends in the scale-up with 57, 23, and 29, respectively. Additionally, having a part-time job positively relates to the number of contacts on Facebook $(p<.001)$, and going to religious meeting places more often positively relates to the scale-up network size $(p<.05)$. These findings are mostly consistent with Hypothesis 1. Particularly entertainment-orientated social foci relate to both outcomes, whereas Facebook ties relate to having a part-time job and people spending more time in religious places have larger scale-up network sizes. The latter finding is consistent with church attendance that positively relates to scale-up network size among American adults (DiPrete et al. 2011).

We also find evidence in support of our conjecture that Dutch majority members have larger social networks than ethnic minority members (H2). Specifically, ethnic minorities have 100 (Facebook) and 125 (scale-up) contacts less than Dutch majority members $(p<.01)$.

Next, we study whether having more co-ethnic classmates (a) and schoolmates (b) positively relates to the extended network size (H3) and we find only moderate-to-no evidence for this conjecture. When respondents have more co-ethnic classmates, their number of Facebook contacts is higher $(p<.05)$.

\section{Romantic Partners}

We find that those who are in a romantic relationship have a larger extended network size but only on Facebook (H4). Those in a romantic relationship have approximately 30 Facebook contacts more than those we are not in a romantic relationship. We find no statistically significant relation between the scale-up measure of the extended social network size and having a partner.10 


\section{Education and Gender}

We find that those in higher educational tracks have larger networks compared to those in the lowest track in the scale-up measure of network size. Specifically, those in the vocational educational tracks have approximately 122-130 contacts less than those in the Senior general or in the University preparatory track (both $p$-values $<.01$ ) as measured via the scale-up method. Overall, this is evidence in support of our conjecture that individuals in higher educational track levels have larger extended networks than those in lower educational track levels (H5), but only so among the scale-up network size.

The results also suggest that girls have larger extended networks than boys, based on both the number of Facebook contacts and the number of contacts in the scale-up measure, consistent with our intuition (H6). Specifically, girls seem to have approximately 31 (Facebook) and 144 (scale-up) contacts more than boys have (both $p<.001$ ).

\section{Confounding Factors}

We observe that early rather than late adopters of Facebook $(<2010)$ and those who spend more time on Facebook have larger numbers of Facebook, consistent with our intuitions. Additionally, those adolescents who are younger have more contacts on Facebook, consistent with prior findings that age relates to the extended network size (Lubbers et al. 2019).

\section{Facebook Vis-à-vis Scale-up}

Next, we compare how our covariates relate to differences in the two metrics. The analyses presented in Table 5 regresses the difference between the Facebook and Scale-up network size (Facebook-Scale-up) on our covariates. Substantively, this means we show for which individuals 
the Facebook network size is closer to the scale-up network size. We present the Heckman selection model for parsimony with prior analyses, but an uncorrected, linear regression model provides similar results (i.e., $\rho \neq 0$ cannot be rejected).

Some findings stand out compared to others. First, those with a part-time job have Facebook networks closer to the size of the scale-up method compared to those without; second, girls' number of Facebook contacts is closer to their scale-up network size compared to the differences among boys $(p<.001)$; third, those in the highest educational track have a Facebook network size closer to their scale-up network size compared to those in the lowest track $(p<.01)$; and fourth, early rather than later Facebook adopters have Facebook network sizes closer to the size of the scale-up method $(p<.001)$. 
Table 5. Maximum-likelihood estimation results of the differences between the Facebook and scaleup network size using Heckman selections.a

\begin{tabular}{|c|c|c|c|}
\hline & \multicolumn{2}{|c|}{ Facebook-Scale-up } & \multirow[b]{2}{*}{$p$-value } \\
\hline & Coef. & $\mathrm{SEb}$ & \\
\hline Constant & 154.340 & 383.446 & 0.687 \\
\hline \multicolumn{4}{|l|}{ Foci } \\
\hline Going out & 18.664 & 15.728 & 0.235 \\
\hline Associations & 18.318 & 9.978 & 0.066 \\
\hline Concerts & 31.500 & 20.042 & 0.116 \\
\hline Family & 22.881 & 17.265 & 0.185 \\
\hline Religious meeting places & 21.531 & 13.833 & 0.120 \\
\hline Job (yes/no) & -51.465 & 23.445 & 0.028 \\
\hline \multicolumn{4}{|l|}{ Similarity of cont. } \\
\hline Ethnic minority (ref. maj.) & 24.247 & 50.499 & 0.631 \\
\hline \# Co-ethnic Class & -2.959 & 3.411 & 0.386 \\
\hline \# Co-ethnic School & 0.053 & 0.029 & 0.067 \\
\hline Romantic partner (ref. None) & -24.928 & 27.603 & 0.366 \\
\hline \multicolumn{4}{|l|}{ Education } \\
\hline Vocational (ref.) & Ref. & Ref. & Ref. \\
\hline Senior general & -12.831 & 29.482 & 0.663 \\
\hline University prep. & -114.764 & 35.099 & 0.001 \\
\hline Girl (ref. Boy) & -91.672 & 23.246 & $<.001$ \\
\hline \multicolumn{4}{|l|}{ Confounders } \\
\hline \multicolumn{4}{|l|}{ Early adopter of FB } \\
\hline No (ref.) & Ref. & Ref. & Ref. \\
\hline Yes & 52.364 & 19.577 & $<0.007$ \\
\hline Non-participation w2 & 103.512 & 62.534 & 0.098 \\
\hline \multicolumn{4}{|l|}{ Hours FB per day } \\
\hline$<1$ hour (ref.) & Ref. & Ref. & Ref. \\
\hline 1-2 hours & -4.972 & 25.173 & 0.843 \\
\hline 2-3 hours & 15.767 & 38.052 & 0.679 \\
\hline 3-4 hours & 21.966 & 72.334 & 0.761 \\
\hline$>4$ hours & 98.922 & 72.804 & 0.174 \\
\hline Non-participation w2 & 95.548 & 186.958 & 0.609 \\
\hline Age in months & 1.268 & 1.634 & 0.438 \\
\hline Observations & 5468 & & \\
\hline Censored observations & 3381 & & \\
\hline Uncensored observations & 2087 & & \\
\hline Log pseudolikelihood & -19368 & & \\
\hline$\rho$ & -0.002 & & \\
\hline
\end{tabular}

\section{CONCLUSIONS}

Social contacts lend support (Lubbers et al. 2019), advice (McPherson et al. 2006), and grant resourceful connections to unknown groups (Granovetter 1973). There are only few substantive papers on individual variation (but see DiPrete et al. 2011; Lubbers et al. 2011) in the extent of social ties beyond the closest ones, likely due to methodological issues. Here, we set out to address 
this and answered two questions. What explains individual variation in the extended network size? And can we provide some insight into the number of Facebook ties vis-à-vis the scale-up network size? Using large-scale, longitudinal data of thousands of Dutch adolescents and linking it to behavioral data from an online network, we answered these questions and contributed to recent sociological work into variation in extended network sizes (DiPrete et al. 2011; Lubbers et al. 2019).

How large are extended social networks according to our sample? We found a median of approximately 351 Facebook contacts, whereas the median extended social network size using the scale-up method was 892. Our estimation of the scale-up network size is substantially higher compared to prior work using the scale-up method solely among adults, showing extended network sizes in the range of 472-610 (e.g., Zheng et al. 2006; McCormick et al. 2010; DiPrete et al. 2011; Lubbers et al. 2019). This discrepancy is perhaps due to our adolescent sample that may be highly socially active across a wide array of foci. The scaling factor of the number of Facebook contacts to the network scale-up network size (2.54) approximates that reported by Hampton and colleagues (2011) (2.83).

Over and beyond such point estimates, however, investigating individual variation in network size provides useful knowledge on societal integration and its group differences. So which adolescents have larger extended social networks? We turned to literature on tie-generating mechanisms among core ties (e.g., Blau 1977; Feld 1981). Consistent with fundamental prior work, we hypothesized and corroborated that those who spend more time in foci indeed have larger extended networks, particularly with respect to social activities such as sporting associations or going out. We reaffirm the relevance of theories on participation in social spaces on the genesis of social ties among acquaintances. 
In addition, we expected and found that adolescents who were ethnic minority members had smaller networks than those with Dutch backgrounds, consistent with prior work on adult racial minorities (DiPrete et al. 2011). Ethnic minorities seem to draw fewer ties rather than dissimilar ties from the opportunity set in their extended social networks. By and large, theories on the interplay between opportunities and homophily are key to theorize about and explain the core as well as the extended network size.

Adolescents in a romantic relationship (only on Facebook), higher educated, and girls have a larger network sizes than their counterparts, consistent with our hypotheses and prior work on adults (Van Tubergen et al. 2016). Differences in recall abilities or social activities may explain gender and educational differences in extended network sizes.

Finally, we pinpointed differences between the scale-up and Facebook network size. Perhaps the two network sizes capture two distinct network layers in Dunbar's sense given their absolute difference (Dunbar et al. 2015) and some individuals may have more overlap between the layers than others. Girls, higher educated, those with a part-time job, and earlier Facebook adopters have network layers that are less-distal. Some post-hoc intuitions may substantiate these findings. For instance, some foci (jobs, being on Facebook longer) may cause a larger part of the outer network layer (i.e., scale-up) to be considered important enough to be Facebook contacts. Additionally, some groups (higher educated and girls) may find it important to have a larger part of that outer layer as Facebook contacts.

There are several limitations to this study that merit acknowledgement. First, data on a more-general target population (e.g., adults) would be ideal. As of yet, however, we do not know of other data that combine surveys - including a scale-up measurement - and behavioral data from online networks. Here, we tentatively assume that the network generation processes are equivalent 
between adults and adolescents. This may be reasonable, because the theoretical mechanisms we describe are general in nature and not necessarily limited to either adult or adolescent populations. But because of this assumed equivalence, we view this study as a next step between the lack of systematic studies on measuring and explaining the extended network size and future studies considering more-general target populations. Additionally, using a different set of scale-up prompts - for instance, "Henk" or "Klaas," which are Dutch names prevalent in older subpopulations - may shift the point estimate of the network scale-up network size to be lower in our sample of youngsters (i.e., they know less of these X's).

Second, our point estimate of the scale-up network size among adolescents was substantially higher compared to those generally found among adult samples. Our conjecture is that this discrepancy is because adolescents may be more socially active than adults. Yet, because there are few studies that employ scale-up methods among adolescents, it is challenging to compare our point estimate to an adolescents baseline estimate. Our high point estimate might result from some unknown issue with using scale-up modules among adolescents. In this study, we were mainly focused on variation in extended social network sizes. So even when an unforeseen scale-up/adolescent issue artificially inflates our point estimate of the extended network size among adolescents, the variation in extended network size between adolescents may persist qualitatively without that inflation. We would commend future research addressing this issue.

Third, we have no longitudinal network data to model (potentially) causal relations or to unravel micro-mechanisms for the genesis of these social ties. We commend future work that gathers multiple waves of behavioral data on the number of contacts on Facebook to study such processes more directly and is able to unravel explicit rather than implicit micro-mechanisms. For 
instance, through gathering complete Facebook networks of a cohort of adolescents and then applying exponential random graph modelling techniques (e.g., see Wimmer and Lewis 2010).

Fourth, limiting scale-up contacts exclusively to persons "known in the Netherlands" ignores transnational ties. However, our approach considers the "meaningful acquaintances" in the national context key in sociological literature and it is methodologically imperative to have a reference population. Yet, future endeavors could include scale-up questions where in each subsequent battery respondents have to recall contacts in increasingly larger geographical regions: neighborhood, city, focal country, neighboring countries, and so forth. One can then compare size estimates across regions to pinpoint if they vary.

Fifth, a growing body of psychological literature studies personality factors (extraversion/agreeableness) and network size (Selden and Goodie 2018). Our data did not include questions on such factors, even though engagement in social foci may be exogenous to them. We commend future research that uses data that capture a broad range of social foci as well as personality factors to disentangle their correlations with the extended network size.

Finally, in this paper, we mostly tested existing explanations for the number of core contacts in the context of extended social network sizes. Future research could identify unique explanations to the extended social network size that do not apply to core networks, or vice versa. One such endeavour could be to gather information about core and extended networks. One can then investigate which covariates relate to the core and not the extended network size (or vice versa) or examine the extent to which some covariates relate to core or extended network sizes. 


\section{ENDNOTES}

1. The validity of an increase in social isolation in McPherson et al. (2006) is controversial (McPherson, Smith-Lovin, and Brashears 2009; Fischer 2009). Paik and Sanchagrin (2013) show that the increase is due to interviewer effects.

2. 150 is the maximum number of stable relationships humans are argued to be able to cognitively manage (Dunbar 1998; Kanai et al. 2012) - coined "Dunbar's Number." There is quite some variation surrounding the point estimates of the distinct network layers (e.g. 5, 15, etc.). For instance, Pollet et al. (2011) find that the support group (mean =7) ranges from 0 to 25 .

3. People highly vary in what they consider important topics to discuss (Bearman and Parigi 2004). Additionally, the use of core discussion ties to measure the number of strong ties has recently come under scrutiny. Small and colleagues $(2013,2015)$ demonstrate that discussion partners are either knowledgeable on the discussion topic or readily available in the social context (doctors, coworkers), but these persons are not necessarily strong relationships among individuals.

4. One may argue that Hypotheses 5 and 6 contradict if education is considered a power/status characteristic. Among teenagers, however, power dynamics surrounding gender are ingrained early on and play a strong role during upbringing and adolescence. Educational track-level, in contrast, only recently started to play a role among our sample of teenagers. Moreover, status or "coolness" among teenagers may be higher among those in lower educational tracks. Hence, status/power differences along educational lines play a much stronger role a later life stages compared to gender.

5. Six hundred respondents in wave 1 were sampled who were not part of the random sampling frame. This was because some schools wanted to participate with more than the two randomly drawn classrooms. Therefore, a random sample of 4,363 pupils was established in wave 1 . Because 
of attrition rates between waves $1,2,3$, and 4 , the representativeness of the sample cannot be guaranteed. We include as many respondents as possible in the sample for analyses, including newcomers (nonrandom) and the nonrandom sample of wave 1 to ensure a large sample size.

6. The collection and use of the DFS for science purposes were approved by an ethical review board for the social and behavioral sciences.

7. The standard error for the basic scale-up estimator is calculated as follows (McCormick et al. 2010: 60):

$$
\mathrm{SE}\left(\text { Scale-up degree }_{i}\right)=\sqrt{\text { Scale-up degree }_{i}} \times \sqrt{\frac{1-\sum_{k=1}^{K} N_{k} / N}{\sum_{k=1}^{K} N_{k} / N}} .
$$

8. One might argue that the Facebook network size could capture fictive accounts inflating the Facebook network size, or that not limiting the Facebook networks to the Dutch population complicates comparisons with the scale-up method. The network size of this study correlates nearperfectly with the network size filtered for Dutch names (so only including realistic names) that occur at least five times $(r=.99)$. Hence, we assume that if there are fictive accounts that they are relatively randomly distributed and filtering for frequently occurring names does not substantively change results.

9. We regressed the scale-up network size on several transformations of the number of Facebook contacts to find out whether they relate linearly or not: we regressed the scale-up network size on quadratic, cubic, logarithmic, and exponential transformations of the Facebook network size and on Facebook networks with more than 50, 100, or 200 contacts. The linear count of the Facebook network size fits these regression models best.

10. A confounding factor for the relation between romantic partners and extended network sizes may be adolescent popularity - i.e., those who are more popular are more likely to enter romantic relationship but also have more friends. As such, we investigated whether our patterns of results 
were robust such "Adolescent popularity" (Mean $=1.755 ; \mathrm{SD}=2.760)$ - i.e., the number of nominations an individual adolescent receives from other students on the survey question "Who are the most popular students in your class?" Our results on romantic partners are robust to either in- or excluding that covariate.

\section{REFERENCES}

Assendorpf, Jens B. and Susanne Wilpers. 1998. "Personality Effects on Social Relationships." Journal of Personality and Social Psychology 74(6):1531-1544.

Bastani, Susan. 2007. "Family Comes First: Men’s and Women's Personal Networks in Tehran." Social Networks 29:357-374.

Bearman, Peter and Paolo Parigi. 2004. "Cloning Headless Frogs and Other Important Matters: Conversation Topics and Network Structure.” Social Forces 83(2):535-557.

Blau, Peter M. 1977. “A Macrosociological Theory of Social Structure.” American Journal of Sociology 83(1):26-54.

Bloothooft, Gerrit and David Onland. 2011. "Socioeconomic Determinants of First Names." Names: A Journal of Onomastics 59(1):25-41.

Bobbitt-Zeher, Donna. 2007. "The Gender Income Gap and the Role of Education.” Sociology of Education 80(1):1-22.

Brashears, Matthew E., Emily Hoagland, and Eric Quintane. 2016. "Sex and Network Recall Accuracy." Social Networks 44:74-84.

Burt, Ronald S. 1984. "Network Items and the General Social Survey.” Social Networks 6(4):293339. 
Currarini, S., Jackson, M.O., Pin, P. 2010. "Identifying the Roles of Race-Based choice and Chance in High School Friendship Network Formation." Proceedings of the National Academy of Sciences 107(11):4857-4861.

De Sola Pool, Ithiel. and Kochen, Manfred. 1978/1979. “Contacts and Influence.” Social Networks 1: 5-51.

DiPrete, Thomas A., Andrew Gelman, Tyler H. McCormick, Julian Teitler, and Tian Zheng. 2011. "Segregation in Social Networks Based on Acquaintanceship and Trust." American Journal of Sociology 116(4):1234-1284.

Duggan, Maeve, Ellison, Nicole B., Lampe, Cliff, Lenhard, Amanda, Madden, Mary. 2015. “Social Media Update 2014.” Pew Research Center.

Dunbar, Robert I.M. 1998. “The Social Brain Hypothesis.” Evolutionary Anthropology 6(5):178190.

2016. "Do Online Social Media Cut Through the Constraints that Limit the Size of Offline Social Networks.” Royal Society Open Science 3:150292.

Dunbar, Robert I.M., Valerio Arnaboldi, Marco Conti, and Andrea Passarella. 2015. "The Structure of Online Social Networks Mirrors Those in the Offline World.” Social Networks 43:39-47.

Ellison, Nicole B., Steinfield, Charles, Lampe, Cliff. 2007. “The Benefits of Facebook 'Friends': Social Capital and College Students' Use of Online Social Network Sites.” Journal of Computer-Mediated Communication 12(4):1143-68.

Ellison, Nicole B., Steinfield, Charles, Lampe, Cliff. 2011. "Connection Strategies: Social Capital Implications of Facebook-Enabled Communication Practices." New Media \& Society 13(6):873-982. 
Feehan, Dennis M. and Matthew J. Salganik. 2016. “Generalizing the Network Scale-Up Method: A New Estimator for the Size of Hidden Populations.” Sociological Methodology 46(1):153186.

Feld, Scott L. 1981. "The Focused Organization of Social Ties.” American Journal of Sociology 86(5):1015-1035.

. 1982. "Social Structural Determinants of Similarity Among Associates." American Sociological Review 47(6):797-801.

Fischer, Claude S. 2009. "The 2004 GSS Finding of Shrunken Social Networks: An Artifact?" American Sociological Review 74(4):657-69.

Freeman, L. and Thompson, C.L. 1989. "Estimating Acquantanceship Volume.” In M. Kochen (Ed.), The Small World (147-158). Norwood, NJ: Ablex Publishing Corporation.

Gonçalves, Bruno, Nicola Perra, and Allessandro Vespignani. 2011. “Modeling Users' Activity on Twitter Networks: Validation of Dunbar's Number." PLoS ONE 6(8):e22656.

Gurevich, Michael. 1961. The Social Structure of Acquaintanceship Networks. Cambridge: Massachusetts Institute of Technology, Dissertation.

Granovetter, Mark S. 1973. "The Strength of Weak Ties." American Journal of Sociology 78(6):1360-1380.

Halberstam, Yosh and Brian Knight. 2016. "Homophily, Group Size, and the Diffusion of Political Information in Social Networks: Evidence From Twitter.” Journal of Public Economics 143:73-88.

Hampton, Keith H., Laurent F. Sessions Goulet, and Kristen Purcell, K. 2011. "Social Networking Sites and Our Lives." Pew Research Center. Retrieved September 19, 2019. (www.pewinternet.org/2011/06/16/social-networking-sites-and-our-lives/) 
Hampton, Keith H., Lauren F. Sessions, and Eun Ja Her. 2011. "Core Networks, Social Isolation, and New Media." Information, Communication \& Society 14(1):130-155.

Heckman, James J. 1979. "Sample Selection Bias as a Specification Error." Econometrica 47(1):153-161.

Holt-Lunstad, Julianne, Timothy B. Smith, and J. Bradley Layton. 2010. "Social Relationships and Mortality Risk: A Meta-Analytic Review.” PLoS Medicine 7(7):e1000316.

Hill, Russel A. and Robin I.M. Dunbar. 2003. "Social Network Size in Humans.” Human Nature 14(1):53-72.

Jaspers, Eva and Frank van Tubergen. 2014. "Children of Immigrants Longitudinal Survey in the Netherlands (CILSNL) - Wave 4. Full version v4.0.0. » DANS.

.2017. "Thematic Collection: Children of Immigrants Longitudinal Survey in the Netherlands (CILSNL). “DANS.

Kadushin, Charles. 2012. Understanding Social Networks: Theories, Concepts, and Findings. Oxford: Oxford University Press.

Kalmijn, Matthijs. 1998. "Intermarriage and Homogamy: Causes, Patterns, Trends." Annual Review of Sociology 24:395-421. .2003. "Shared Friendship Networks and the Life Course: An Analysis of Survey Data on Married and Cohabiting Couples.” Social Networks 25(3):231-249.

Kalter, Frank, Anthony Heath, Miles Hewstone, Jan O. Jonsson, Matthijs Kalmijn, Irena Kogan, and Frank van Tubergen. 2015. "Children of Immigrants Longitudinal Survey in Four European Countries (CILS4EU). ZA5353, Data file version 2.1.0.” GESIS Data Archive, Cologne [distributor]. 
Kanai, Ryota, Bahador Bahrami, Rebecca Roylance, and Geraint Rees, G. 2012. “Online Social Network Size is Reflected in Human Brain Structure." Proceedings of the Royal Society B: $1-8$.

Killworth, Peter D., Eugene C. Johnsen, Christopher McCarty, Gene Ann Shelley, and H. Russel Bernard. 1998a. "A Social Network Approach to Estimating Seroprevalence in the United States." Social Networks 20:23-50.

Killworth, Peter D., Christopher McCarty, H. Russel Bernard, and Eugene C. Johnsen. 1998b. "Estimation of Seroprevalence, Rape, and Homelessness in the United States Using a Social Network Approach.” Evaluation Review 22:289-308.

Lubbers, Miranda J., José Luis Molina, Hugo Valenzuele-García. 2019. "When Networks Speak Volumes: Variation in the Size of Broader Acquaintanceship Networks." Social Networks $56: 55-69$.

Mouw, Ted. and Barbara Entwisle. 2006. "Residential Segregation and Interracial Friendship in Schools.” American Journal of Sociology 112(1):394-441.

Maltiel, Rachael, Adrian E. Raftery, Tyler H. McCormick, and Aaron J. Baraff. 2015. "Estimating Population Size Using the Network Scale-Up Method." The Annals of Applied Statistics $9(3): 1247-1277$.

Maltiel, Rachael and Aaron J. Baraff. 2015. "NSUM: Network Scale Up Method. R package version 1.0." Retrieved from: https://CRAN.R-project.org/package=NSUM.

Marsden, Peter V. 1987. "Core Discussion Networks of Americans.” American Sociological Review 52(1):122-131.

Mayer, Adalbert, Puller, Steven L. 2008. “The Old Boy (and Girl) Network: Social Network Formation on University Campuses." Journal of Public Economics 92(1-2):329-47. 
McCarty, Christopher, Peter D. Killworth, Russel H. Bernard, Eugene C. Johnsen, and Gene Ann Shelley. 2001. "Comparing Two Methods for Estimating Network Size." Human Organization 60(1):28-39.

McCormick, Tyler H., Matthew J. Salganik, and Tian Zheng. 2010. “How Many People Do You Know? Efficiently Estimating Personal Network Size.” Journal of the American Statistical Association 105(489):59-70.

McPherson, Miller, Lynn Smith-Lovin, and James M. Cook. 2001. "Birds of a Feather: Homophily in Social Networks." Annual Review of Sociology 27:415-444.

McPherson, Miller, Lynn Smith-Lovin, and Matthew E. Brashears. 2006. "Social Isolation in America: Changes in Core Discussion Networks over Two Decades.” American Sociological Review 71(3):353-375.

.2009. "Models and Marginals: Using Survey Evidence to Study Social Networks." American Sociological Review 74(4):670-681.

Meertens Institute. 2016. "De Nederlandse Voornamenbank." Retrieved September 6, 2016. (http://www.meertens.knaw.nl/nvb/)

Mollenhorst, Gerald, Beate Volker, and Henk Flap. 2008. "Social Contexts and Personal Relationships: The Effect of Meeting Opportunities on Similarity for Relationships of Different Strength.” Social Networks 30(1):60-68.

Moore, Gwen. 1990. "Structural Determinants of Men's and Women's Personal Networks." American Sociological Review 55(5):726-735.

Paik, Athony and Kenneth Sanchagrin. 2013. "Social Isolation: An Artifact." American Sociological Review 78(3):339-360. 
Parigi, Paolo and Warner Henson II. 2014. "Social Isolation in American." Annual Review of Sociology 40:153-171.

Peterson, Richard A. 1992. "Understanding Audience Segmentation: From Elite and Mass to Omnivore and Univore.” Poetics 21(4):243-258.

Pollet, Thomas V., Sam G.B. Roberts, and Robin I.M. Dunbar. 2011. "Use of Social Network Sites and Instant Messaging Does Not Lead to Increased Offline Social Network Size, or to Emotionally Closer Relationships with Offline Network Members.” Cyberpsychology, Behavior, and Social Networking 114(4):253-258.

Pool, Ithiel de Sola and Manfrew Kochen. 1978. "Contacts and Influence.” Social Networks 1:551.

Reich, Stephanie M., Kaveri Subrahmanyam, Guadalupe Espinoza. 2012. "Friending, IMing, and Hanging Out Face-to-Face: Overlap in Adolescents' Online and Offline Social Networks.” Developmental Psychology 48(2):356-68.

Roberts, Sam G.B., Ruth Wislon, Pawel Fedurek, Robin I.M. Dunbar. 2008. "Individual Differences and Personal Social Network Size and Structure.” Personality and Individual Differences 44(4):954-964.

Roberts, Sam. G.B. and Robin I.M. Dunbar. 2011. Communication in Social Networks: Effects of Kinship, Network Size, and Emotional Closeness. Personal Relationships 18(3):439-452.

Rözer, Jesper Jelle, Gerald Mollenhorst, and Beate Volker. 2015. "Romantic relationship formation, maintenance and changes in personal networks." Advances in life course research 23:86-97.

Schimmer, Paulien and Frank van Tubergen. 2014. "Transnationalism and Ethnic Identification Among Adolescent Children of Immigrants in the Netherlands, Germany, England, and Sweden.” International Migration Review 48(3):680-709. 
Selden, Mary and Adam S. Goodie. 2018. "Review of the Effects of Five Factor Model Personality Traits on Network Structures and Perceptions of Structure.” Social Networks 52:81-99.

Selfhout, Maarten, William Burtk, Susan Branje, Jaap Denissen, Marcel van Aken, and Wim Meeus. 2010. "Emerging Late Adolescent Friendship Networks and Big Five Personality Traits: A Social Network Approach.” Journal of Personality 78(2):508-538.

Simpson, Brent, Barry Markovsky, and Mike Steketee. 2011. "Power and the Perception of Social Networks." Social Networks 33:166-171.

Slater, Philip E. 1963. “On social regression.” American Sociological Review 28(3):339-364.

Small, M.L. 2013. "Weak Ties and the Core Discussion Networks: Why People Regularly Discuss Important Matters With Unimportant Alters.” Social Networks 35(5):470-483.

Small, Mario L., Vontrese D. Pamphile, Peter McMahan. 2015. "How Stable is the Core Discussion Network?" Social Networks 40:90-102.

Smith, Sanne, Ineke Maas, and Frank van Tubergen. 2012. "Irreconcilable Differences? Ethnic Intermarriage and Divorce in the Netherlands, 1995-2008." Social Science Research 41(5):1126-1137.

.2014. "Ethnic Ingroup Friendships in Schools: Testing the By-Product Hypothesis in England, Germany, the Netherlands and Sweden.” Social Networks 39:33-45.

Statistics Netherlands. 2012. "Migranten, Vreemdelingen en Vluchtelingen: Begrippen op het Terrein van Asiel en Buitenlandse Migratie.” Retrieved June 16, 2015 (http://www.cbs.nl) .2015. CBS Statline: Bevolking; kerncijfers. Retrieved March 23, 2015

(http://statline.cbs.nl) 
Subrahmanyam, Kaveri, Stephani M. Reich, Natalia Waechter, Guadalupe Espinoza. 2008.

“Online and Offline Social Networks: Use of Social Networking Sites by Emerging Adults." Journal of Applied Developmental Psychology 29(6):420-33.

Van Tubergen, Frank. 2014. "Size and Socio-Economic Resources of Core Discussion Networks in the Netherlands: Differences by National-Origin Group and Immigrant Generation." Ethnic and Racial Studies 37(6):1020-2042.

Van Tubergen, Frank, Obaid A. Al-Modaf, Nora F. Almosaed, Mohamed B.S. Al-Ghamdi 2016. "Personal Networks in Saudia Arabia: The Role of Ascribed and Achieved Characteristics." Social Networks 45:45-54.

Tulin, Marina, Thomas V. Pollet, and Nale Lehmann-Willenbrock. 2018. "Perceived Group Cohesion Versus Actual Social Structure: A Study Using Social Network Analysis of Egocentric Facebook Networks.” Social Science Research 74:161-175.

Wimmer, Adreas and Kevin Lewis. 2010. "Beyond and Below Racial Homophily: ERG Models of a Friendship Network Documented on Facebook." American Journal of Sociology 116(2):583-642.

Van Zalk, Maarten H. W., Nejra van Zalk, Margaret Kerr, and Hakan Stattin. 2014. "Influences between Online-Exclusive, Conjoint and Offline-Exclusive Friendship Networks: The Moderating Role of Shyness.” European Journal of Personality 28(2):134-46.

Sapiezynski, Piotr, Arkaduisz Stopczynski, David K. Wind., Jure Leskovec., and Sune Lehmann. 2018. "Offline Behaviors of Online Friends.” arXiv: 1811.03153.

Zheng, Tian, Matthew T. Salganik, and Andrew Gelman. 2006. "How Many People Do You Know in Prison?" Journal of the American Statistical Association 101(474):409-423. 


\section{APPENDICES}

\section{Appendix A. Populations and Their Sizes in the Scale-up Categories in the Netherlands}

Table A1 provides an overview of the total population numbers in the Netherlands that are used as the X's in our scale-up method questions in the survey.

Table A1. The used scale-up populations in 2014 (Population in the Netherlands in 2014=16,829,289)

\begin{tabular}{ll}
\hline X's prompted in the survey & X's in the populationa,b \\
\hline 1. Thomas & 40538 \\
2. Kevin & 23162 \\
3. Anne & 29720 \\
4. Melissa & 11706 \\
5. Moham(m)ed & 13443 \\
6. Arrested & 251900 \\
7. Jailed & 10365 \\
8. Groningen & 198317 \\
9. Utrecht & 328164 \\
10. Maastricht & 122488 \\
11. Den Haag & 508940 \\
12.Zwolle & 123159 \\
13. MBO (tertiary lower-vocational) & 497319 \\
14. HBO (tertiary higher-vocational) & 440293 \\
15. University & 250186 \\
\hline
\end{tabular}

a Firstname population estimates are from Meertens Institute (2016); b City, police, and tertiary education estimations are from Statistics Netherlands (2015). 


\section{Appendix B. Additional Sensitivity Checks on the Data}

Because the network scale-up method is sensitive to outliers we examined the "seriousness" of respondents' answers to the questionnaire. Specifically, we investigate whether there are "straightlining" respondents - i.e., respondents that tick the same box for each of a set of items belonging together. We calculated for items that belong to a battery of questions (e.g., several items measuring "health behavior") whether there were respondents that had a standard deviation of zero on their answers to these items. If a respondent has a standard deviation of zero it means that he/she ticked the boxes of all items in a measurement similarly. In total there were seven batteries of questions, containing 36 items that were not part of different routing options in the questionnaire. Of the 4,073 respondents in wave 4, four respondents (about $0.1 \%$ ) had a row standard deviation of zero on all seven batteries of questions.

In a less rigid sample selection of scoring a standard deviation of zero over, for instance, three batteries of questions, we end up with the same four respondents. A visual inspection of these respondents' answers to other survey questions also showed careless responses. We did not consider these four respondents in the analyses, as they likely provided inaccurate answers that may disproportionately affect our results. 


\section{Appendix C. The Scale-Up Model With Three Adjustments and Sensitivity Analyses}

Equations 1 through 3 analytically summarize the scale-up model proposed by Maltiel et al. (2015). It adjusts the basic scale-up estimator of Equation (2) in the main text in three ways. Maltiel et al. (2015) specify this model in a more detail than we do here. But we can summarize the model as follows:

$$
\begin{gathered}
y_{i k} \sim \operatorname{Binom}\left(d_{i}, \tau_{k} q_{i k}\right), \\
d_{i} \sim \log -\operatorname{Normal}\left(\mu, \sigma^{2}\right), \\
q_{i k} \sim \operatorname{Beta}\left(m_{k}, \rho_{k}\right),
\end{gathered}
$$

where $y_{i k}$ is the predicted number of individuals known by $i$ in group $k, d_{i}$ is the basic scale-up estimate from Equation (2), and $q_{i k}$ is the probability that person $i$ knows someone from group $k$, which is allowed to vary randomly across individuals. $d_{i}$ follows a log-normal distribution (which is statistically suitable according to Maltiel et al., 2015), and the priors $\mu$ and $\sigma$ follow from fitting the basic scale-up estimator in Equation (2) (see Equation (6) for $\sigma$ ), and $q_{i k}$ follows a Beta distribution arriving at $m_{k}$ and $\rho_{k}$ using predefined priors or priors from Equation (2). Finally, $\tau_{k}$ is a multiplier for transmission bias, which is 1 for known populations and less than or equal to 1 for groups of unknown size. The 1 for known populations (no transmission error) is reasonable, as these groups are often less stigmatized than unknown populations. The "NSUM" package defaults to $\tau_{k}=0.5$, but we experimented with two additional multipliers $\tau_{k}$ for the unknown population of choice (in the main analyses: individuals in prison), and in each trial, using either $0.5,0.75$, or 1 (while keeping other parameters equal) results were similar as those found in the main analysis. We keep $\tau_{k}$ at the 0.5 default for the main analyses presented in the paper. 


\section{Appendix D. Estimation of the Extended Social Network Size Using Linear Regressions}

Table D1 shows linear regression models for the Facebook network size and the scale-up network size. It highlights the importance of accounting for sample (scale-up) and sample and privacy selection (Facebook), as some covariates change direction when one lacks to account for such biases (gender, scale-up; ethnic background, scale-up; education, both measures).

Table D1. Linear regression results of the extended network size measured via the number of Facebook friends and the scale-up method

\begin{tabular}{|c|c|c|c|c|c|c|}
\hline & \multicolumn{3}{|l|}{ Facebook } & \multicolumn{3}{|l|}{ Scale-up } \\
\hline & Coef. & $\mathrm{SEa}$ & $p$-value & Coef. & Sea & $p$-value \\
\hline Constant & 359.134 & 106.422 & 0.001 & 170.697 & 316.051 & 0.590 \\
\hline \multicolumn{7}{|l|}{ Foci (H1) } \\
\hline Going out & 60.103 & 5.049 & $<0.001$ & 76.816 & 11.988 & $<0.001$ \\
\hline Associations & 20.170 & 3.504 & $<0.001$ & 40.613 & 7.988 & $<0.001$ \\
\hline Concerts & 15.325 & 6.558 & 0.021 & 50.573 & 15.595 & 0.002 \\
\hline Family & 5.409 & 4.348 & 0.216 & 35.429 & 12.770 & 0.006 \\
\hline Religious meeting places & 4.406 & 4.880 & 0.369 & 30.540 & 11.946 & 0.012 \\
\hline Job (yes/no) & 26.826 & 7.697 & 0.001 & -4.865 & 17.372 & 0.780 \\
\hline \multicolumn{7}{|l|}{ Similarity of cont. $(\mathrm{H} 2+\mathrm{H} 3)$} \\
\hline Ethnic minority (ref. maj.) & 24.784 & 17.654 & 0.163 & 71.626 & 43.525 & 0.103 \\
\hline \# Co-ethnic Class & 1.454 & 0.985 & 0.143 & -0.843 & 3.116 & 0.787 \\
\hline \# Co-ethnic School & -0.009 & 0.013 & 0.485 & 0.048 & 0.029 & 0.101 \\
\hline Rom. partner (yes/no) (H4) & 37.887 & 8.419 & $<0.001$ & 15.773 & 23.634 & 0.506 \\
\hline \multicolumn{7}{|l|}{ Education (H5) } \\
\hline Vocational (ref.) & Ref. & Ref. & Ref. & Ref. & Ref. & Ref. \\
\hline Senior general & -2.426 & 17.877 & 0.892 & -30.645 & 27.798 & 0.273 \\
\hline University prep. & -42.336 & 11.223 & $<0.001$ & -173.587 & 37.843 & $<0.001$ \\
\hline Girl (ref. Boy) (H6) & 26.152 & 8.740 & 0.003 & -43.237 & 18.075 & 0.018 \\
\hline \multicolumn{7}{|l|}{ Confounders } \\
\hline \multicolumn{7}{|l|}{ Early adopter of FB } \\
\hline No (ref.) & Ref. & Ref. & Ref. & - & - & - \\
\hline Yes & 65.509 & 7.033 & $<0.001$ & - & - & - \\
\hline Non-participation w2 & 48.813 & 32.749 & 0.139 & - & - & - \\
\hline \multicolumn{7}{|l|}{ Hours FB per day } \\
\hline$<1$ hour (ref.) & Ref. & Ref. & Ref. & - & - & - \\
\hline $1-2$ hours & 43.002 & 10.346 & $<0.001$ & - & - & - \\
\hline $2-3$ hours & 58.769 & 13.394 & $<0.001$ & - & - & - \\
\hline 3-4 hours & 76.847 & 25.459 & $<0.001$ & - & - & - \\
\hline$>4$ hours & 71.546 & 28.774 & 0.014 & - & - & - \\
\hline Non-participation w2 & 11.545 & 9.530 & 0.228 & - & - & - \\
\hline Age in months & -1.657 & 0.447 & $<0.001$ & 0.909 & 1.367 & 0.508 \\
\hline Observations & 2687 & & & 3120 & & \\
\hline Adjusted $\mathrm{R}_{2}$ & 0.192 & & & 0.077 & & \\
\hline
\end{tabular}




\section{Appendix E. Selection Equation Outcomes}

Table E1 provides the selection equation results of our Heckman selection models. What we observe is that ethnic minorities are far less likely to be have an observed Facebook network size. Additionally, ethnic minorities, boys, and lower educated are less likely to have an observed scaleup network size.

Table E1. Selection part of the Heckman selection model in Table 4.

\begin{tabular}{lllllll}
\hline \hline & Facebook & & & \multicolumn{2}{l}{ Scale-up } & \\
& Coef. & SE & $p$-value & Coef. & SE & $p$-value \\
\hline Constant & 0.077 & 0.040 & 0.054 & -0.046 & 0.048 & 0.347 \\
Ethnic minorities (ref. maj.) & -0.557 & 0.049 & $<0.001$ & -0.293 & 0.044 & $<0.001$ \\
Girls (ref. Boys) & 0.018 & 0.041 & 0.650 & 0.287 & 0.035 & $<0.001$ \\
Education & & & & & & \\
$\quad$ Vocational (ref.) & Ref. & Ref. & Ref. & Ref. & Ref. & Ref. \\
$\quad$ Senior general & 0.133 & 0.070 & 0.056 & 0.213 & 0.058 & $<0.001$ \\
$\quad$ University prep. & 0.035 & 0.046 & 0.444 & 0.423 & 0.053 & $<0.001$ \\
\hline
\end{tabular}

